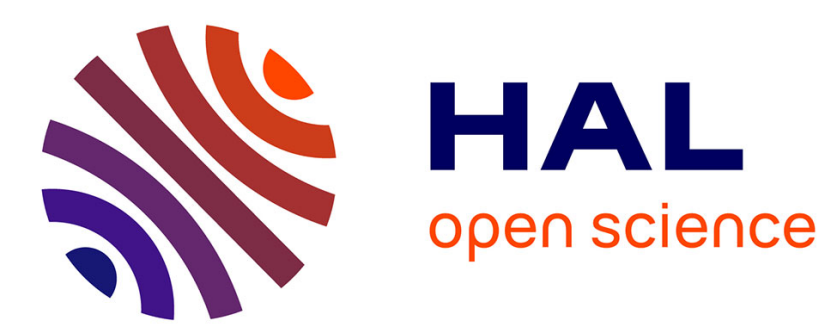

\title{
Novel Nanocomposites Based on Polyurethane and Micro Fibrillated Cellulose
}

M. Özgür Seydibeyoğlu, Kristiina Oksman

\section{To cite this version:}

M. Özgür Seydibeyoğlu, Kristiina Oksman. Novel Nanocomposites Based on Polyurethane and Micro Fibrillated Cellulose. Composites Science and Technology, 2008, 68 (3-4), pp.908. 10.1016/j.compscitech.2007.08.008 . hal-00498994

\section{HAL Id: hal-00498994 \\ https://hal.science/hal-00498994}

Submitted on 9 Jul 2010

HAL is a multi-disciplinary open access archive for the deposit and dissemination of scientific research documents, whether they are published or not. The documents may come from teaching and research institutions in France or abroad, or from public or private research centers.
L'archive ouverte pluridisciplinaire HAL, est destinée au dépôt et à la diffusion de documents scientifiques de niveau recherche, publiés ou non, émanant des établissements d'enseignement et de recherche français ou étrangers, des laboratoires publics ou privés. 


\section{Accepted Manuscript}

Novel Nanocomposites Based on Polyurethane and Micro Fibrillated Cellulose

M. Özgür Seydibeyoğlu, Kristiina Oksman

PII: $\quad$ S0266-3538(07)00326-0

DOI: $\quad$ 10.1016/j.compscitech.2007.08.008

Reference: CSTE 3799

To appear in: $\quad$ Composites Science and Technology

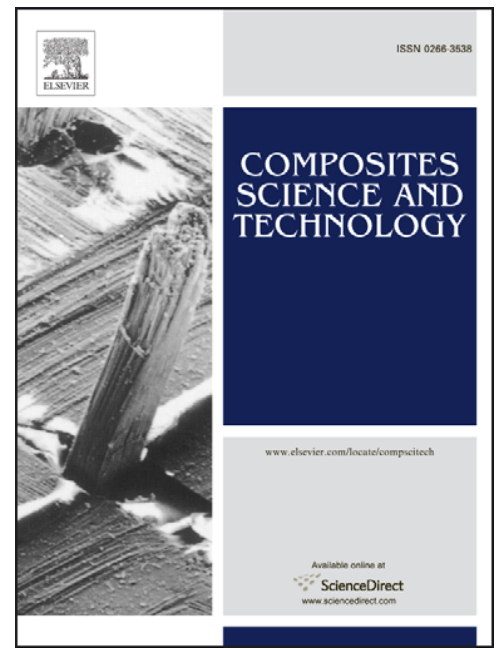

Received Date: $\quad 11$ January 2007

Revised Date: $\quad 30$ July 2007

Accepted Date: $\quad 10$ August 2007

Please cite this article as: Seydibeyoğlu, M.., Oksman, K., Novel Nanocomposites Based on Polyurethane and Micro Fibrillated Cellulose, Composites Science and Technology (2007), doi: 10.1016/j.compscitech.2007.08.008

This is a PDF file of an unedited manuscript that has been accepted for publication. As a service to our customers we are providing this early version of the manuscript. The manuscript will undergo copyediting, typesetting, and review of the resulting proof before it is published in its final form. Please note that during the production process errors may be discovered which could affect the content, and all legal disclaimers that apply to the journal pertain. 


\title{
Novel Nanocomposites Based on Polyurethane and Micro
}

\section{Fibrillated Cellulose}

\author{
M.Özgür Seydibeyoğlu ${ }^{1)}$ and Kristiina Oksman ${ }^{2)}$ \\ 1) Department of Materials Science and Engineering, Istanbul Technical University, Istanbul, Turkey \\ 2) Division of Manufacturing and Design of Wood and Bionanocomposites, Luleå University of \\ Technology, Skellefteå, Sweden
}

\begin{abstract}
The goal of this study was to fibrillate cellulose from micro to nano scale and evaluate how these microfibers and nanofibrils affected the mechanical and thermal properties of thermoplastic polyurethane. The source of cellulosic material was hard wood cellulose fibers and the fibrillation was done with a high pressure homogenizer. The composite materials were prepared using compression moulding, by stacking the cellulose fiber mats between polyurethane films. The results showed that both microfibers and nanofibrils reinforced the polyurethane and provided better heat stability. The addition of $16.5 \mathrm{wt} \%$ of cellulose nanofibrils to PU increased the strength nearly $500 \%$ and the stiffness by $3000 \%$. These results are very promising in terms of obtaining fibrils with a novel processing method and by improving the mechanical and thermal properties of polyurethane. This is expected to expand the application areas of polyurethanes.
\end{abstract}

Key words: cellulose A, composites A, mechanical properties B, microstructure D, fibrillation $\mathrm{E}$ 


\section{INTRODUCTION}

The use of nanoreinforcements in the polymer matrix will lead to nanocomposite materials with better properties than the neat polymers [1]. It has been reported that the nanoreinforcements can increase the strength without sacrificing the elongation of the materials [2]. In some nanocomposite materials, the nanoreinforcements have shown to increase the strength and the modulus at the same time [3]. The reasons for the reported improvements is that nano size reinforcements have much higher surface area than the conventional microcomposites and the defects in the reinforcing phase are reduced at the nano level [4]. Further the polymer does not lose its transparency because the fibers or particles which have diameter less than one tenth of the visible light are not affected from the light scattering [5]. The above properties of the nanoreinforcements have motivated the materials scientists to develop nanocomposites for the next generation composite materials.

Cellulose materials which can be prepared at the nano size as well, has attracted attention for reinforcing different polymers [1, 3, 6-8]. Cellulose is a polymer which can be found in the nature abundantly and can be obtained from many various plants and living organisms $[9,10]$. Cellulose is light and environment friendly and also biodegradable. It has low cost, high specific strength and modulus. It has interesting sound insulation properties and low thermal conductivity [11]. 
Wood is one of the main resources for the cellulose. The wood contains hemicellulose and lignin with cellulose. The cellulose is purified with certain processes. The pure cellulose can be used for many different applications. The cellulose or wood polymer composites always face the interfacial problem due to the cellulose being hydrophilic and polar and the polyolefins being hydrophobic [12]. In this study hydrophilic polyurethane has been used as the matrix polymer. In previous studies on polymer-wood composites, isocyanate, which is the major constituent of the polyurethanes, has been used as binder at the interface [13]. When the polyurethane is used as matrix, it is believed that no adhesion problem would occur and the dispersion would be much better.

Polyurethanes are an interesting family of polymers which have been used in many different applications such as biomedical, coatings, adhesives and composites [14, 15]. Polyurethanes form a copolymer structure with the isocyanates as hard domains and polyols as soft domains [16]. The properties of the polyurethanes can be adjusted mainly by two routes. The first route is based on the chemistry of polyurethanes formulating the polyurethane based on different isocyanate/polyol ratio and using different amounts of chain extender. The second route is altering the properties of the polyurethanes with different fillers and reinforcements [16]. Polyurethanes have been reinforced with certain fillers such as talc, mica and glass fiber in the form of polymer matrix composite material [16]. These materials increase the tensile strength but decrease the elongation to break and discolour the polymer $[2,4]$. 
The aim of this study was to examine the effect of fibrillation of cellulose fibers using a high pressure homogenizer and compare the reinforcing effect of micro sized and nano sized cellulose fibrils in the polyurethane matrix. Earlier studies made on polyurethane and cellulose both as micro- and nanocomposites have been reported [3, 17-18] but nanofibrils prepared by high pressure homogenizer has not been utilized in a polyurethane matrix before.

\section{EXPERIMENTAL}

\section{Materials}

Hard wood cellulose fibers (CF), $\left(\right.$ Terracel $^{\mathrm{TM}}$, Rayonier, USA) has been used as obtained from the supplier but also used as raw material for the preparation of the nano sized fibrils.

The polyurethane (PU) has been obtained from Flokser Co (Flokser Company, Istanbul, Turkey). It is synthesized with MDI (Methyl-diphenyl-diisocyanate) and polyol and chain extended with 1,4 butanediol. The polymer has a $\mathrm{Tg}$ value at $-48{ }^{\circ} \mathrm{C}$ and a molecular weight of 30,000 . The polyurethane polymer has been obtained in the form of thin films $(60 \mu \mathrm{m})$ from the supplier.

\section{Preparation of nanofibrils}

The starting materials were pellets of hard wood cellulose fibers. The cellulose pellets were dispersed in water with a concentration of $0.2 \mathrm{wt} \%$ forming a slurry. This slurry was stirred continuously for two days to obtain dispersed cellulose fibers. The fibrillation 
of cellulose fibers was made using a high pressure homogenizer (APV-Invensys 2000). This type of homogenizer is usually used for homogenizing emulsions and fluids with different particulates for food applications. The slurry was passed through the valves that apply the high pressure. The maximum pressure of the used homogenizer is $1000 \mathrm{bar}$ but in this study a pressure between 250 and 500 bar was used. A schematic picture of the homogenizer is shown in Fig. 1.

Pressure, concentration of cellulose-water slurry and pumping cycles were varied to optimize the fibrillation effect of cellulose fibers.

\section{Preparation of nonwoven mats of cellulose fibers and fibrils}

The nonwoven mats of cellulose fibers and nanofibrils were formed by filtering the water-cellulose slurry. For the cellulose fibers, a plastic mesh was used for drying and forming the mat. The slurry was agitated during the filtering process to distribute the cellulose fibers evenly on the mesh. The cellulose fibers formed mat with strong hydrogen bonds [19] and the mat could easily be peeled off from the mesh after drying. The thickness of the fiber mat was adjusted by altering the cellulose concentrations on the water-cellulose slurry. The thickness of the mats varied between 50-250 micronmeter.

The mats of nanofibrils were done with similar procedure except the plastic mesh, which could not be used due to the large size of pores. Therefore a special membrane filter (Pall Life Sciences, Polyethersulfone, 0.1 micron meter) was used for mat formation of fibrils. 
Compression moulding was used to consolidate the stacked films and fiber/fibrilmats. The composite materials with cellulose fibers were translucent whereas the nanocomposites were almost transparent.

\section{Composite preparation}

The composite materials were prepared using film-stacking method. In this method the PU films and non woven cellulose fiber/fibril mats were stacked and compression moulded (Fontijne Grotnes B.V., Vlaardingen, The Netherlands). The temperature (150 $\left.200{ }^{\circ} \mathrm{C}\right)$, pressure (100 -200 bar) and compression time ( $1-4$ minutes) were varied to find the optimum composite properties. The compression moulding conditions were optimized to $175^{\circ} \mathrm{C}$ at 100 bar for $1 \mathrm{~min}$ and $30 \mathrm{sec}$. The compositions are shown in Table 1.

\section{Characterization}

The structure of the cellulose fiber before and after the homogenization process was observed with visual examination, optical microscopy (OM) and scanning electron microscopy (SEM). The visual examination of fibrillation was done on the cellulosewater slurries. (Leica DC300) optical microscopy was used to characterize the fibrillation of the cellulose and the fibril structure was characterized with a SEM (Hitachi S-4300) operated at $6 \mathrm{kV}$ ). The samples were sputter coated with gold to avoid charging and to make the samples conductive. 


\section{Mechanical Testing}

Tensile properties of the neat polymer and composite materials were measured with a miniature material tester, Mini-Mat 2000 (Rheometric Scientific Ltd, Leatherhead, UK). The measurements were done at $22^{\circ} \mathrm{C}$. Samples dimensions were $0.1 \times 5 \times 50 \mathrm{~mm}$. The maximum strength was obtained from the stress-strain curves. For each composite at least 5 samples were tested.

\section{Dynamic Mechanical Thermal Analysis}

Dynamic Mechanical Thermal Analyzer DMTA V (Rheometric Scientific Ltd, Leatherhead, UK) was used to measure the dynamic modulus of the PU and the composite materials at different temperatures. Materials were tested using tensile mode. The sample size was $0.1 \times 5 \times 40 \mathrm{~mm}$. The frequency was $1 \mathrm{~Hz}$ and the heating rate was 2 ${ }^{\circ} \mathrm{C} / \min$.

\section{RESULTS AND DISCUSSION}

\section{Preparation of nanofibrils}

The cellulose-water slurry was stirred for 2 days. Different cellulose concentrations were tested for the homogenization process, $(0.025,0.05,0.1$ and 0.2$)$. The concentration of 0.025 wt \% was shown to work well in the homogenizer and was chosen as concentration in this study. Different pressures (250 and 500 bar) were tested and it was observed that the higher pressure, 500 bar, was more effective for fibrillation than 250 bar, therefore 500 bar was used in this study. The critical parameter in the homogenization process was 
the number of times the slurry would pass through the homogeniser. The time for one complete cycle was measured and 15 passes were calculated as 15 times the duration of one complete cycle. The fibrillation was done with 0.025 wt \% cellulose slurry at 500 bar and was passed through the homogeniser 15, 30, 45 and 60 times.

\section{Visual examination}

The change in dispersion of the cellulose suspensions after certain passes of homogenisation could be easily observed. Fig.2. shows the suspension after 15, 30, 45 and 60 passes. After 15 passes, the cellulose fibers were not homogenously dispersed in the water, there was a small improvement after 30 passes. After 45 and 60 passes a more colloidal structure was obtained, the fibrils did not sediment as easily on the bottom of the beaker.

\section{Optical Microscopy}

The changes were also observed in the optical microscope. It can be easily seen from Fig. 3, that the cellulose fibers in Fig. $3 b$ are smaller and more fibrillated after the homogenisation process, compared to Fig. 3a. This observation further strengthens the statement of fibrillation of cellulose to nano scale.

\section{Fibril structure}

In Fig. 4, 5, and 6 three different materials are shown. Fig 4, shows the cellulose fiber structure before the fibrillation process. Fig 4a) shows the overview and 4b) a more detailed view of the cellulose fiber structure where it is possible to visualize the 
nanofibrils at the fiber surface. Fig 5 and 6 shows the fibrillated cellulose after the homogenization process, the fibrillation will occur on the individual fibrils which can be seen on the cellulose fiber in detail. The microscopy study showed that it is possible to fibrillate cellulose pulp fibers using a high pressure homogenizer.

Fig. 5 shows the fibrillated structures of the cellulose fibers after 45 passes through the homogenizer. It is possible to see the large difference between the Fig. 4 and 5. The fibers are broken down to the smaller fibers and forming a network of fibrils. Fig 6 shows the effect after 60 passes with further decreased fibril size compared to Fig. 5. It is clearly shown that the homogenization process results in fibrillation of cellulose fibers resulting in small fibrils which are at least partly at nano size. The fibrillated structure can be observed within SEM pictures. The number of passes through the homogenizer does not affect the fibril size after 45 passes but the number of fibrils increased after 60 passes. This is the reason why the 60 passes were chosen as optimum in this study.

\section{Mechanical and thermal properties}

The mechanical properties of neat polyurethane and cellulose fiber polyurethane composites are shown in Table 2. The results show that the mechanical properties of composites were improved with an increase in cellulose fiber content. The increase in the tensile strength was significant which strengthen the hypothesis that polyurethane and cellulose are compatible as they are both hydrophilic. The strength of the PU-CF 2 was increased by $200 \%$ compared with neat PU. The addition of $8.5 \mathrm{wt} \%$ cellulose fibers in PU matrix also increased the E-modulus value by more than $300 \%$ and the higher fiber 
content (18.7 wt \%) increased it by almost $500 \%$. Table 2 shows also the mechanical properties of the nanocomposites. The nanofibrils showed to be more effective reinforcement than the micro sized cellulose fibers. The strength was improved from 5 $\mathrm{MPa}$ for neat PU to $28 \mathrm{MPa}$ (almost 500\%) for the PU-CNF 2 composite, and the modulus was improved from 25 to $725 \mathrm{MPa}$, which is almost $3000 \%$ higher. These results clearly show the effectiveness of nano size reinforcement. The cellulose nano fibrils will integrate within the polymer matrix much better due to the smaller size but this great improvement is also expected due to better properties of nano sized fibrils compared with the micro sized fibers. The increase of the probability of the cellulose linkages can be observed at the nano-scale as well having much smaller particle sizes [20].

The lower mechanical properties of the nanocomposites at lower loading percentage may be due to the poor sample preparation. The fibrils were not homogenously dispersed in the PU matrix at lower loading.

In the earlier studies conducted on polyurethanes and cellulose based fibers all of them are reporting about the mechanical reinforcement $[3,17,21,22]$. Rials and Wolcott [21] tested the composites dynamic mechanical thermal properties and comparing the modulus values and observed an increase in the mechanical properties of PU with wood fibers. Wu et al. [3] and Auad et al. [17] reported improved mechanical properties with the nanosize cellulose whiskers in PU matrix. 
Nakagaito and Yano [23], reported increased mechanical properties with micro fibrillated cellulose in a phenol formaldehyde matrix. In this study the nano sized cellulose microfibrils showed better reinforcement than the micro sized cellulose fibers. This study is very important to show the reinforcing of the nano scale for the polymer matrices.

Fig. 7 shows the storage modulus and tan delta as a function of temperature for pure PU and the composites. The storage modulus in Fig. 7 a) shows that both composites have higher modulus on the entire temperature range compared to pure PU and that the modulus does not drop after the PU softening temperature. The nanocomposite shows highest storage modulus during the entire temperature range, being approximately 2200 \% higher than the neat PU matrix and about $150 \%$ higher than the $\mathrm{CF}$ composites at room temperature.

One of the most interesting results of this study was the large improvement in storage modulus of the nanocomposite compared with neat PU and cellulose fiber composites. This large improvement is expected to be a result of a percolation network formed by cellulose nano fibrils [20]. The strong hydrogen bonds between the cellulose molecules will lead to strong interaction between the fibers and fibrils thus results in much better composite properties compared with the pure PU at higher temperatures. The other important effect is the microfibrillated cellulose has its flexibility. This property of the cellulose fibrils gives a tangling effect with the polymer matrix which will further increase the mechanical properties of the nanocomposite [24]. The composites with cellulose fibers and fibrils show much better temperature stability than PU at room 
temperature because of the percolating network effect and it is maintained even at higher temperatures.

Rials and Wolcott [21] prepared polyurethane-wood fiber composites and observed similar reinforcements with wood fibers but with much higher wood fiber content. They did not test with DMTA in order to observe the behaviour of the composites with increasing temperature. Also Nakagaito and Yano [23] used microfibrillated cellulose to increase the mechanical properties of the phenol formaldehyde but they did not perform DMTA analysis to study the thermal stability of the composites.

This study has shown importance of the microfibrillated cellulose in order to obtain composites with good mechanical properties and increased stability at higher temperatures.

The tan delta of pure PU and the composites is shown in Fig 7 b). The shift in tan delta peak temperature can give an indication of the molecular interaction between two phases. In this study, the tan delta peak did not show any shift which indicate that there are no molecular interaction between the PU and cellulose. Therefore the reinforcing effect and thermal stability is associated mainly with the cellulose network and strong interaction of cellulose particles. 


\section{CONCLUSIONS}

Microfibrillated cellulose was obtained with a novel method using a high pressure homogenizer. The fibrils were characterized and identified to be very small, partly at nanosize by SEM analysis. Fiber/fibril mats were prepared by filtering the slurry and a film-stacking technique was used to prepare the composites. Transparent composite films were obtained with cellulose fibrils.

The matrix polymer (PU) and the prepared composites mechanical and thermal properties were analysed and the results showed that both cellulose fibers and nanofibrils improved the mechanical properties of PU. The most remarkable results were shown in nanocomposites with $16.5 \mathrm{wt} \%$ fibril content. The strength was nearly $500 \%$ and the Emodulus $3000 \%$ better than the matrix polymer. Furthermore the storage modulus of the nanocomposites composites was improved and higher than PU in both elastic and plastic temperature range. When the storage modulus dropped at a temperature of $-46^{\circ} \mathrm{C}$ for neat PU and the cellulose fiber composite at a temperature of $-31{ }^{\circ} \mathrm{C}$, the nanocomposites showed no significant drop in the storage modulus values even at higher temperatures.

Tan delta peak temperature was not changed for the composites compared to PU, which indicates no molecular interaction between the PU and cellulose. 
With these improvements, the use of polyurethane and many other polymers can be expanded. The most important outcome of this study was to understand the importance of nanosize reinforcement for the polymers.

\section{Acknowledgments}

Norwegian Research Council has been greatly acknowledged for the scholarship of the

researcher M.Özgür Seydibeyoğlu to do this study at the Norwegian University of Science and Technology. The authors would also like to thank Rayonier, USA and Flokser Company, Turkey for supplied materials.

\section{REFERENCES}

1. Oksman K, Kvien I, Petersson L, Bondeson D Mathew A P Bionanocomposites COMAT 2005, International Conference on Science and Technology of Composite Materials, 11-14 December 2005, Buenos Aires, Argentina.

2. Vaia R A. Polymer nanocomposites open a new dimension for plastics and composites. The AMPTIAC Newsletter, 2002; 6(1); 17-24.

3. Wu Q, Liu X, Berglund L.A. Polymer nanocomposites based on cellulose. Proceedings of the 23rd Riso International Symposium on Materials Science:Sustainable Natural and Polymeric Composites-Science and Technology, Roskilde, Denmark: 2002. 
4. Sternitzke M, Derby B, Brook R J Alumina/silicon carbide nanocomposites by hybrid polymer/powder processing: microstructures and mechanical properties. J Am Ceram Soc, $1998 ; 81(1) ; 41-48$.

5. Nogi M, Handa K, Nakagaito A N, Yano H Optically transparent bionanofiber composites with low sensitivity to refractive index of the polymer matrix. J Appl Phys Let, 2005; 87(24);1-3.

6. Dweib M A, Hu B, Donnell A O, Shenton HW, Wool R P All natural composite sandwich beams for structural applications. Comp Struct, 2004; 63(2); 147-157.

7. Bhatnagar A, Sain M. Processing of Cellulose Nanofiber-reinfroced Composites. J Reinf Plast Comp, 2005; 24 (12); 1259-1268.

8. Yano H, Nakahara S. Bio-composites produced from plant microfiber bundles with a nanometer unit web-like network. J Mater Sci; 2004; 39(5); 1635-1638.

9. Nakagaito A N, Iwamoto S, Yano H. Bacterial cellulose: The ultimate nano-scalar cellulose morphology for the prodcution of high strength composites. Appl Phys A 2005; 80(1); 93-97.

10. Bledzki A K, Gassan J. Composites reinforced with cellulose based fibres. Prog Polym Sci 1999; 24(2); 221-274.

11. Malainine M, Mahrouz E, Dufresne M A. Thermoplastic nanocomposites based on cellulose microfibrils from Opuntia ficus-indica parenchyma cell. Compos Sci Technol, $2005 ; 65(10) ; 1520-1526$.

12. Bengtsson M, Gatenholm P, Oksman K. The effect of crosslinking on the properties of polyethylene/wood flour composites. Compos Sci Technol, 2005; 65(10); 1468-1479. 
13. Raj R G, Kokta B V, Maldas D., Danealt C. Use of wood fibers in thermoplastics. VII. The effects of coupling agents in polyethylene-wood fiber composites. J Appl Polym Sci, 1989; 7(4); 1089-1103.

14. Moon S Y, Kim J K, Nah C, Lee Y S, Polyurethane/montmorillonite nanocomposites prepared from crystalline polyols, using 1,4-butanediol and organoclay hybrid as chain extenders. E Polym J, 2004; 40 (8); 1615-1621.

15. Gorrasi G, Tortora M, Vittoria V, Synthesis and physical properties of layered silicates/polyurethane nanocomposites. J Polym Sci part B: Polym Phy, 2005; 43(18); 2454-2467.

16. Zhang $\mathrm{X}, \mathrm{Xu} \mathrm{R}, \mathrm{Wu} \mathrm{Z}$, Zhou C. The synthesis and characterization of polyurethane/clay nanocomposites. Polym Int, 2003; 52(5); 790-794.

17. Auad M L, Contos V S, Nutt S, Aranguren M I, Marcovich N E. Polyurethane reinforced with nano/micro sized cellulose fibers. Proceedings of COMAT 2005. International Conference on Science and Technology of Composite Materials: Argentina, 2005, p.35-36.

18. Rials T G, Wolcott M P, Nassar J M. Interfacial contributions in lignocellulosic ufiber-reinforced polyurethane composites. J Appl Polym Sci. 2001; 80(4); 546-555.

19. Dufresne A, Dupeyre D, Vignon M R. Cellulose microfibrils from potato tuber cells: Processing and characterization of starch-cellulose microfibril composites. J Appl Polym Sci, 2000; 76(14); 2080-2092.

20. Samir M A S A, Alloin F, Sanchez J Y, Dufresne A. Cellulose nanocrystals reinforced poly(oxyethylene). Polymer, 2004; 45(12); 4149-4157. 
21. Rials T G, Wolcott M P, Morphology and property relationships in wood-fibre-based polyurethanes. J Mater Sci Let, 1998; 17(4); 317-319.

22. Rivera-Armenta J L, Heinze T, Mendoza-Martnez A M. New polyurethane foams modified with cellulose derivatives. E Polym J, 2004; 40(12); 2803-2812.

23. Nakagaito A N, Yano H. The effect of morphological changes from pulp fiber towards nano-scale fibrillated cellulose on the mechanical properties of high-strength plant fiber based composites. Appl Phys A, 2004; 78(4); 547-552.

24. Angles M N, Dufresne A. Plasticized Starch/Tunicin Whiskers Nanocomposite Materials. 2.Mechanical Behavior. Macromolecules, 2001; 34(9); 2921-2931. 


\section{ACCEPTED MANUSCRIPT}

\section{Table Captions:}

Table 1. The compositions of prepared materials and sample codes

Table 2. The mechanical properties of neat PU and prepared composites 
Table 1. The compositions of prepared materials and sample codes

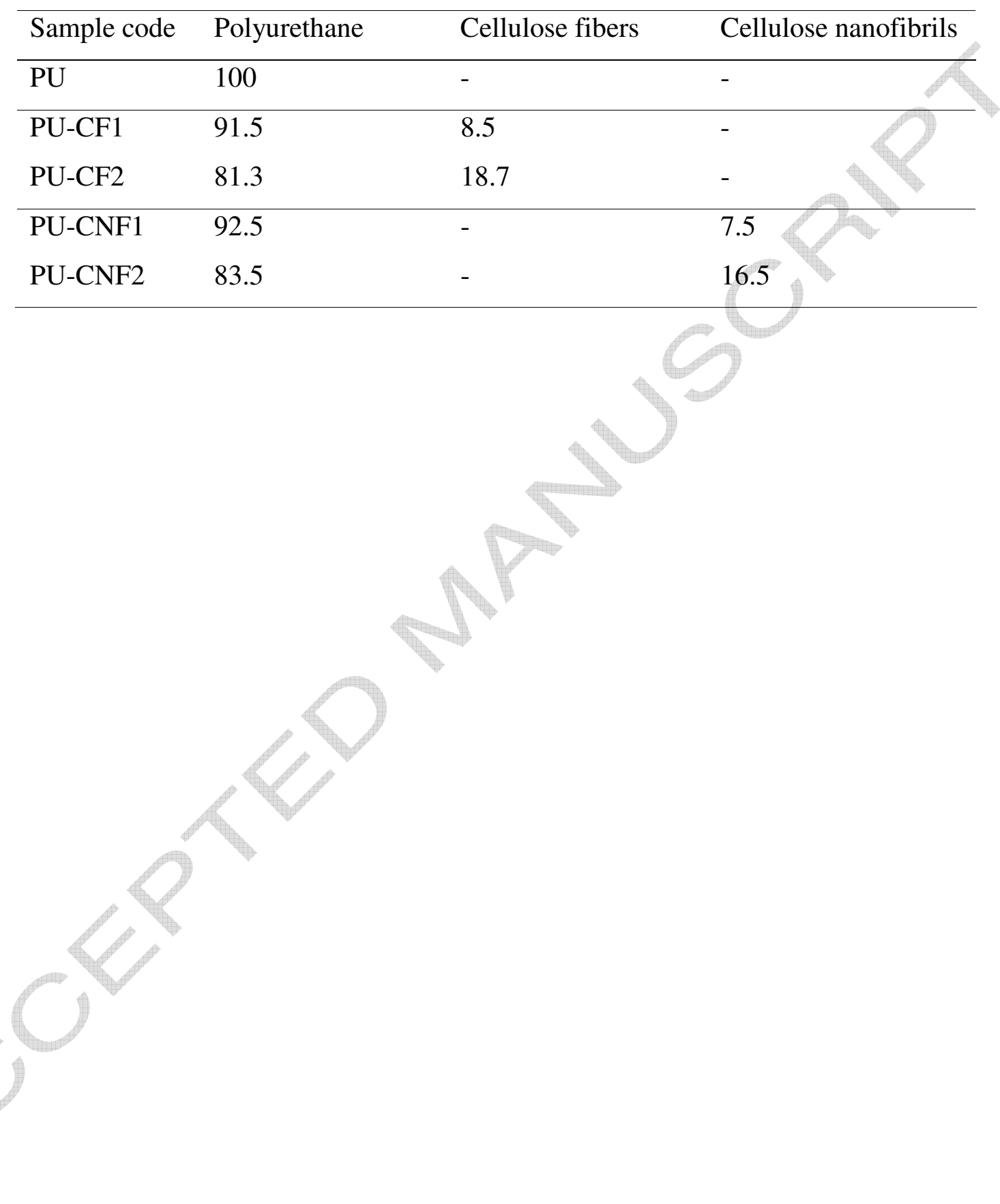




\section{ACCEPTED MANUSCRIPT}

Table 2. The mechanical properties of neat PU and prepared composites

\begin{tabular}{|l|c|c|}
\hline Sample & E-Modulus (MPa) & Max strength (MPa) \\
\hline PU & $25 \pm 0.3$ & $5 \pm 0.4$ \\
\hline PU-CF 1 & $107 \pm 0.8$ & $11 \pm 0.2$ \\
PU-CF 2 & $144 \pm 0.6$ & $15 \pm 0.3$ \\
\hline PU-CNF 1 & $93 \pm 0.7$ & $5 \pm 0.2$ \\
PU-CNF 2 & $725 \pm 1.3$ & $28 \pm 0.5$ \\
\hline
\end{tabular}




\section{Figure Captions:}

Figure 1. A schematic picture of the high pressure homogenizer.

Figure 2. Visual characterisation of the cellulose suspensions $(0.025 \% \mathrm{wt} \%)$ after a) 15 passes, b) 30 passes, c) 45 passes, d) 60 passes through the homogenization process.

Figure 3. The appearance of cellulose fibers a) before and b) after the fibrillation process studied with optical microscope.

Figure 4. The structure of cellulose fibers before the fibrillation process a) overview and b) detailed view.

Figure 5. The fibrillation effect after 45 passes through the homogenization process.

Figure 6. The fibrillation effect after 60 passes through the homogenization process.

Figure 7. DMTA of PU, PU-CF2 and PU-CNF2 a) storage modulus and b) $\tan \delta$ peaks presented a function of temperature. 


\section{ACCEPTED MANUSCRIPT}

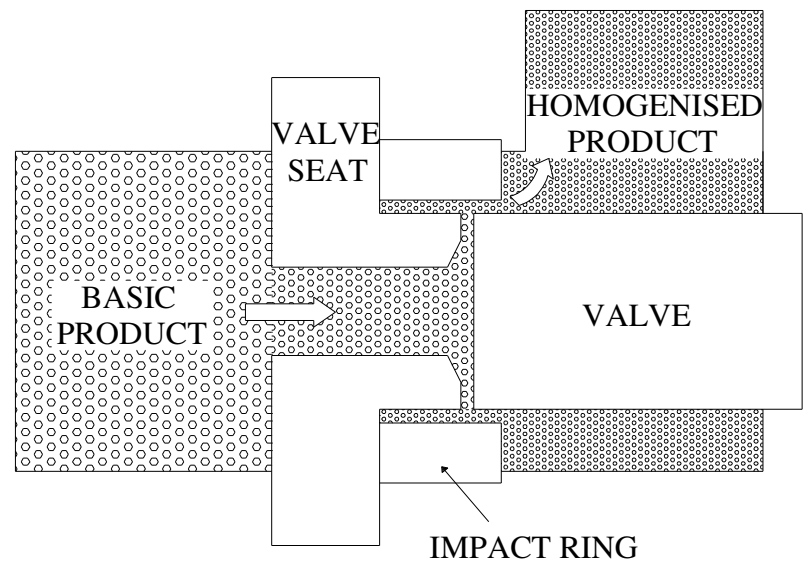

Figure 1. 


\section{ACCEPTED MANUSCRIPT}

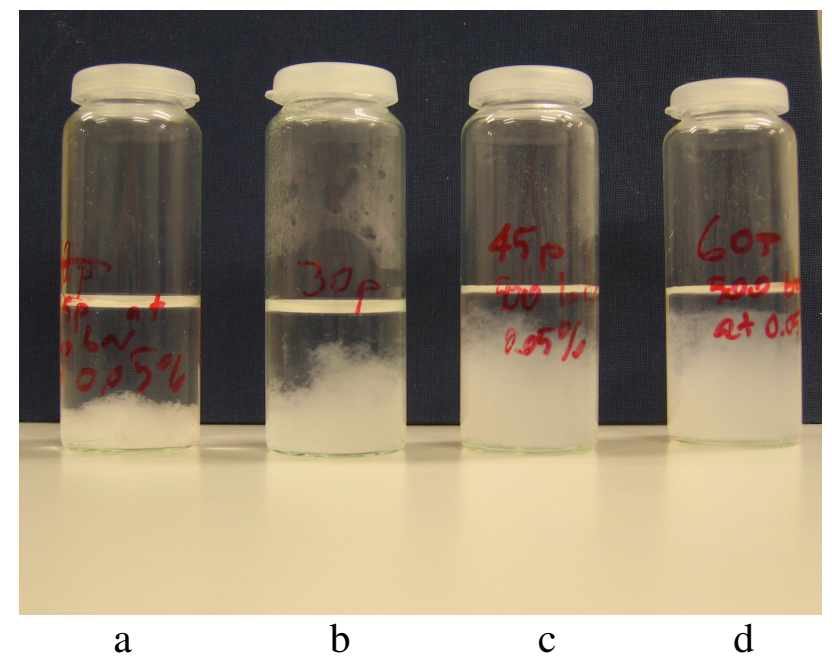

Fig 2. 


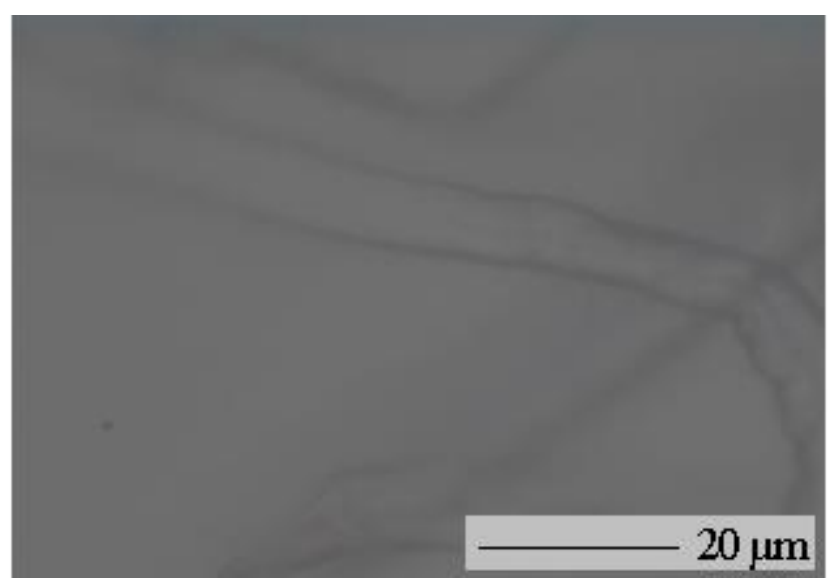

a)

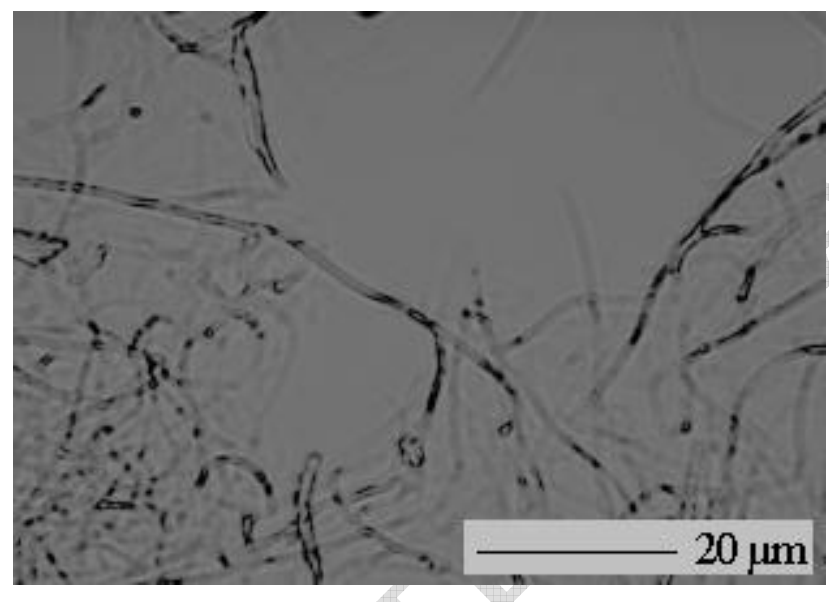

b)

Figure 3.

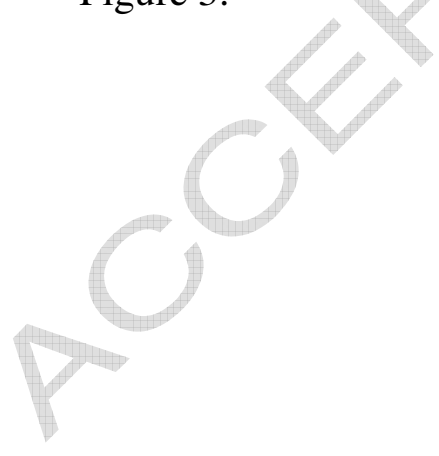




\section{ACCEPTED MANUSCRIPT}

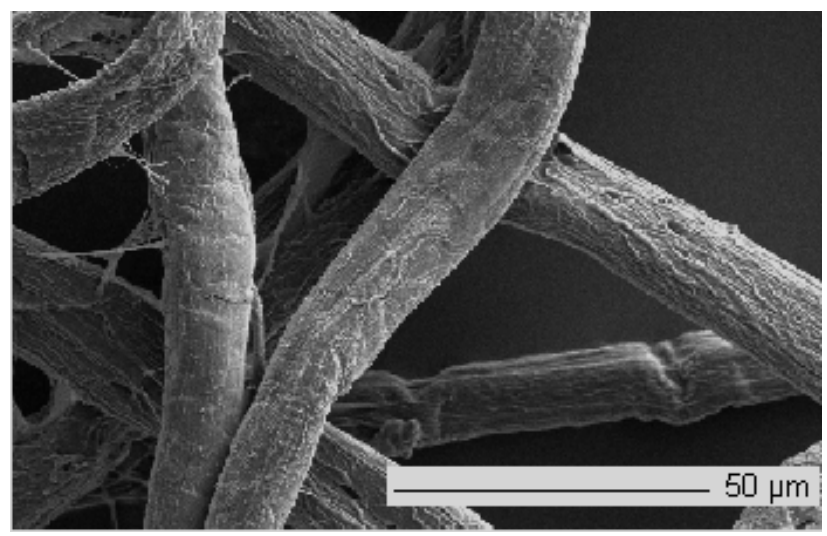

a)

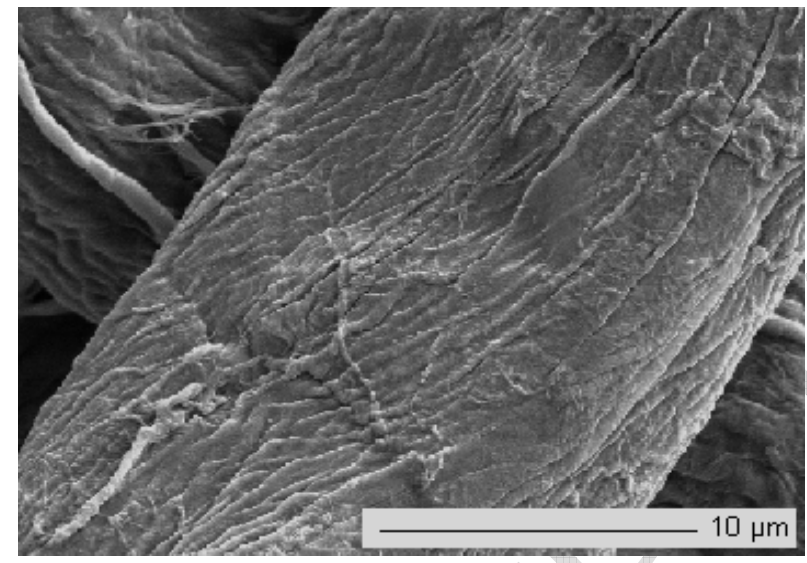

b)

Figure 4. 


\section{ACCEPTED MANUSCRIPT}

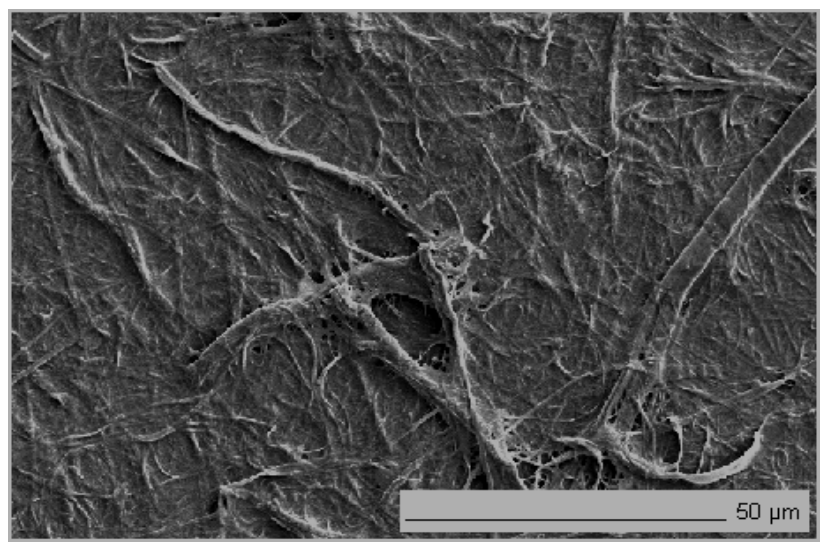

a)

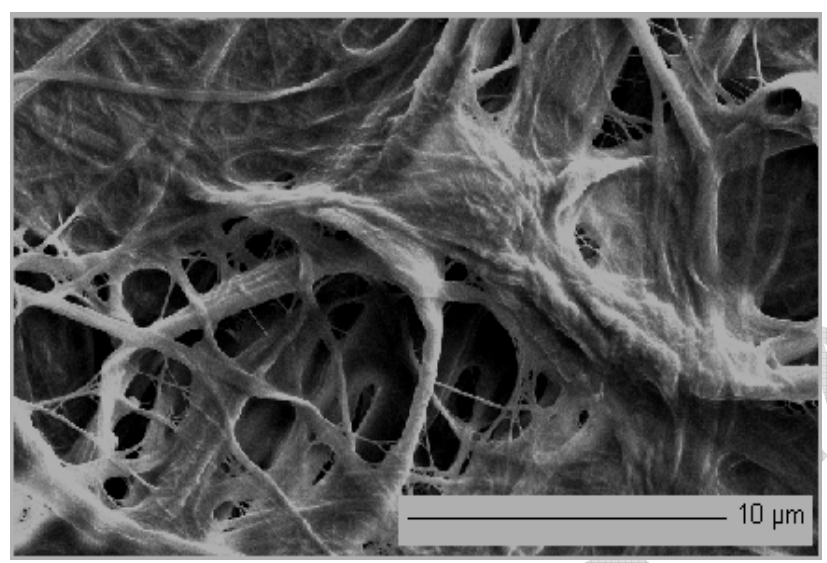

b)

Figure 5.

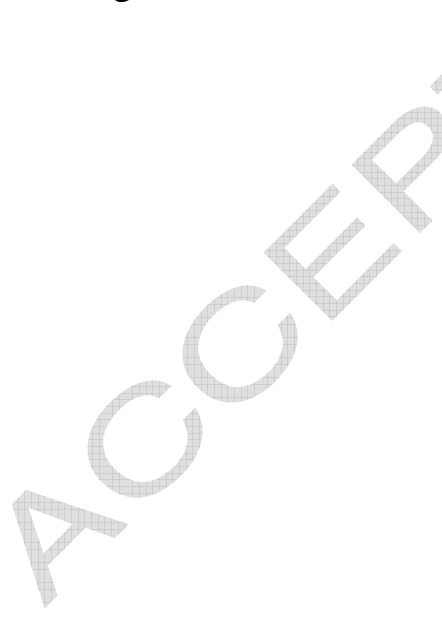




\section{ACCEPTED MANUSCRIPT}

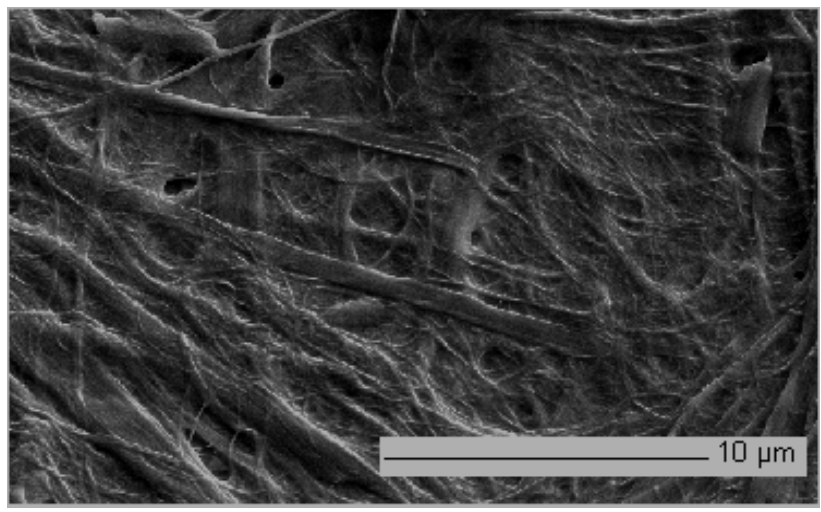

a)
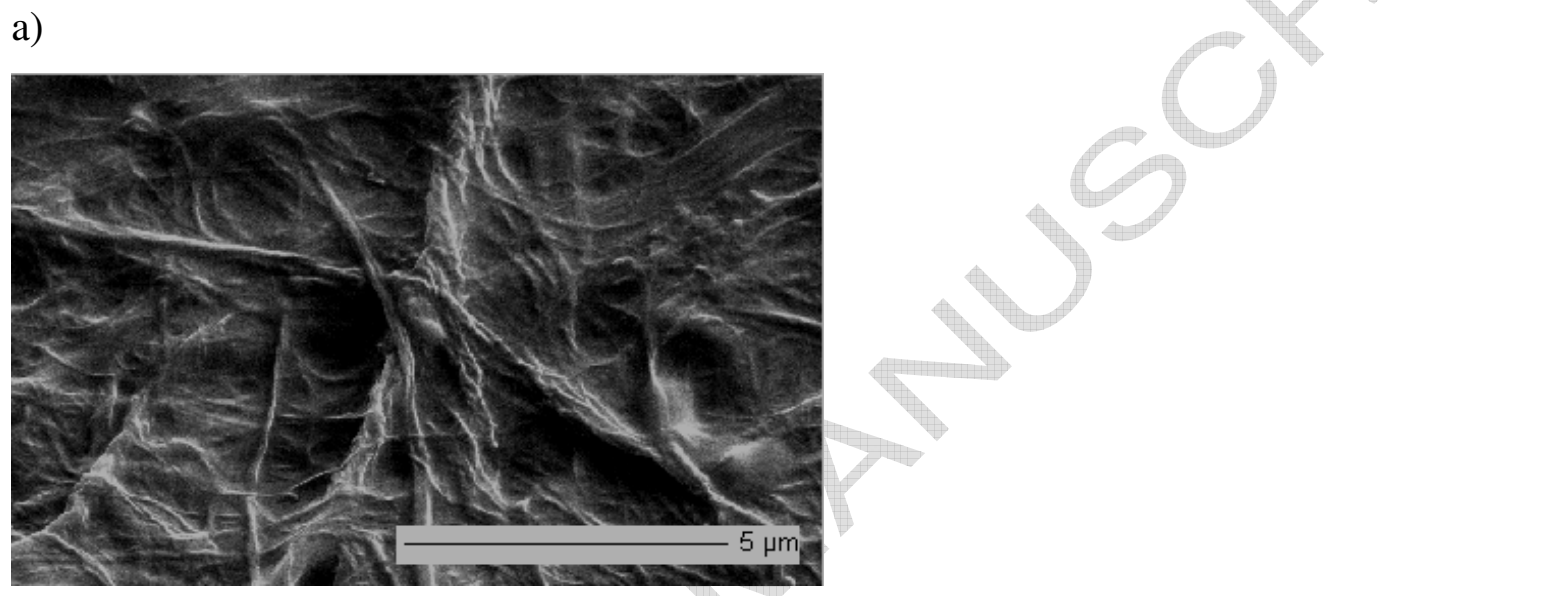

b)

Figure 6.

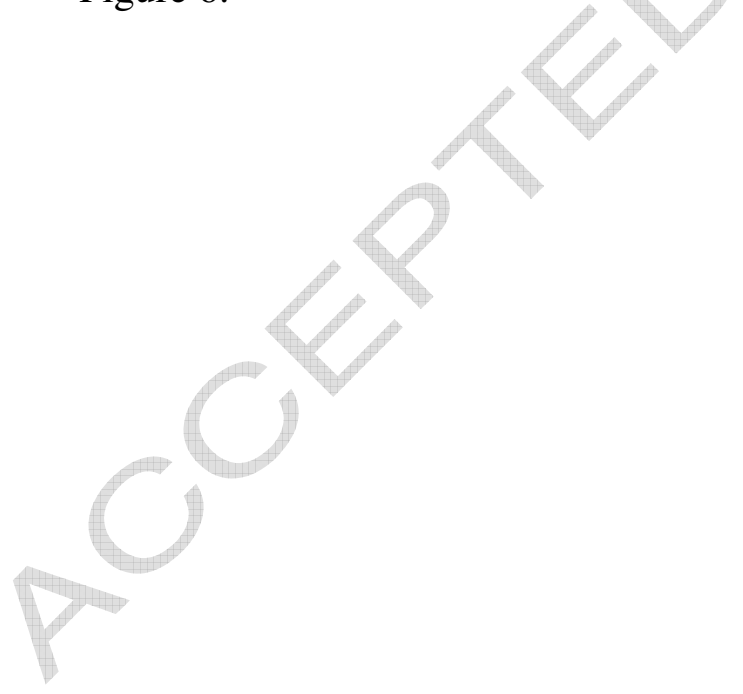




\section{ACCEPTED MANUSCRIPT}

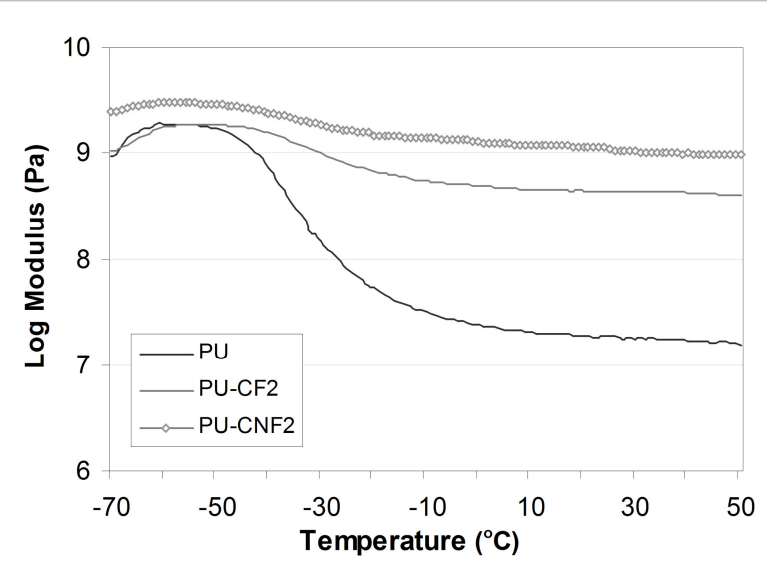

a)

b)

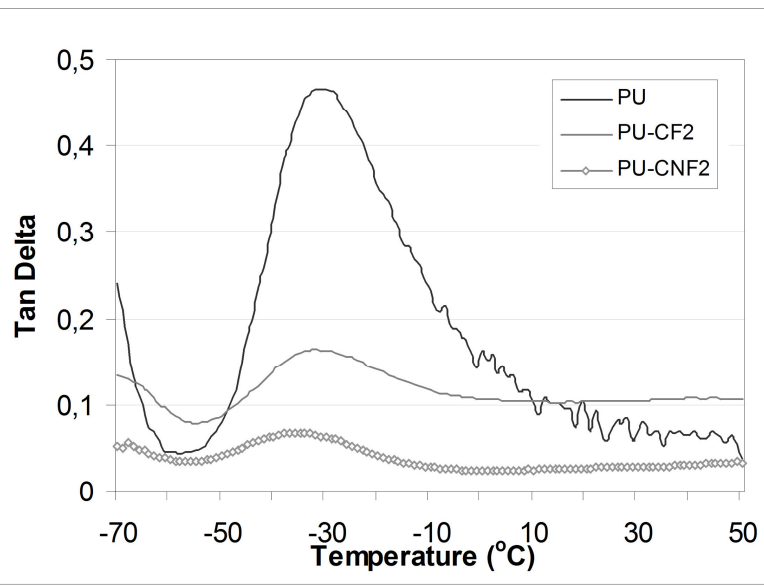

Figure 7. 